\title{
Confocal $\mu$-XRF and $\mu$-XAFS Studies of an Uranium-Rich Sediment from a Nuclear Waste Disposal Natural Analogue Site
}

\author{
Melissa A. Denecke*, Koen Janssens**, Jörg Rothe*, Ulrich Noseck***, Rolf Simon* \\ * Forschungszentrum Karlsruhe, P.O. Box 3640, D-76021 Karlsruhe, Germany \\ ** Department of Chemistry, University of Antwerp, Universiteitsplein 1, B-2610 Antwerp, \\ Belgium \\ ***Gesellschaft für Anlagen- und Reaktorsicherheit (GRS) mbH, Theodor-Heuss-Straße 4, D-38122 \\ Braunschweig, Germany
}

We perform spatially resolved X-ray fluorescence and absorption fine structure investigations with a micrometer-scale resolution ( $\mu$-XRF and $\mu$-XAFS) recorded in a confocal geometry on a bore core section from the uranium-rich tertiary sediment [1]. The aim of this study is to assess mechanisms leading to immobilization of the uranium during diagenesis of the uranium enriched horizon. In order to probe micro-volumes below the sample surface, a confocal irradiation-detection geometry is employed. For this purpose, two half-lenses are used; one is used to focus the primary beam and another collimating half-lens in front of the detector, perpendicular to the first lens [2]. By scanning sample areas at different depths, stacks of tomographic cross sections may be easily recorded. A polycapillary half-lens as well as planar compound refractive lenses are used to focus the beam to a $20 \mu \mathrm{m}$ diameter spot and to an ellipsoid spot with about $2.5 \mu \mathrm{m}$ vertical and $5 \mu \mathrm{m}$ horizontal dimensions, respectively. By varying the energy of the beam at a constant sample position, XAFS spectra are recorded. Both the near edge XAFS (XANES) region and the extended XAFS (EXAFS) energy region are investigated.

U L3 $\mu$-XANES and $\mu$-EXAFS results show uranium to be present as a tetravalent, poorly crystalline phosphate (or sulfate), possibly ningyoite (Fig. 1A\&1B). The U L3 EXAFS is measured in a sample area bordering a lignite inclusion but does not resemble that expected for $U$ ligation with organic material [3]. This suggests that lignite may have not been involved in U immobilization. Stacks of images at different depths reveal uranium to be near both framboidal Fe(II) nodules and to arsenic (Fig. 2). The arsenic present is either $\mathrm{As}(\mathrm{V})$ or $\mathrm{As}(0)$ (Fig. 3); we find no evidence for As(III). As(0) is observed to be intimately associated with the surface of Fe(II) nodules (Fig. 4) and likely arsenopyrite. The U(IV) is associated with $\mathrm{As}(\mathrm{V})$. That $\mathrm{As}(\mathrm{V})$ is found in addition to $\operatorname{As}(0)$, even in volumes probed below the surface, combined with the observation that the $\operatorname{As}(\mathrm{V})$ is associated with $U$ hot spots allows to propose that arsenic was involved in the U(VI) immobilization during diagenesis. We propose a hypothesis for the mechanism of uranium immobilization, where arsenopyrite acted as reductant of ground water dissolved U(VI) leading to precipitation of less soluble U(IV) and thereby forming As(V).

References

[1] M.A. Denecke, K. Janssens, K. Proost, J. Rothe, U. Noseck, Environ. Sci. Technol. (in print).

[2] K. Janssens, K. Proost, G. Falkenberg, Spectrochim. Acta B 59 (2004), 1637.

[3] See, e.g., M.A. Denecke et al., Radiochim. Acta 79 (1997)151.

[4] HASYLAB and ANKA are gratefully acknowledged for allotment of beamtime. 

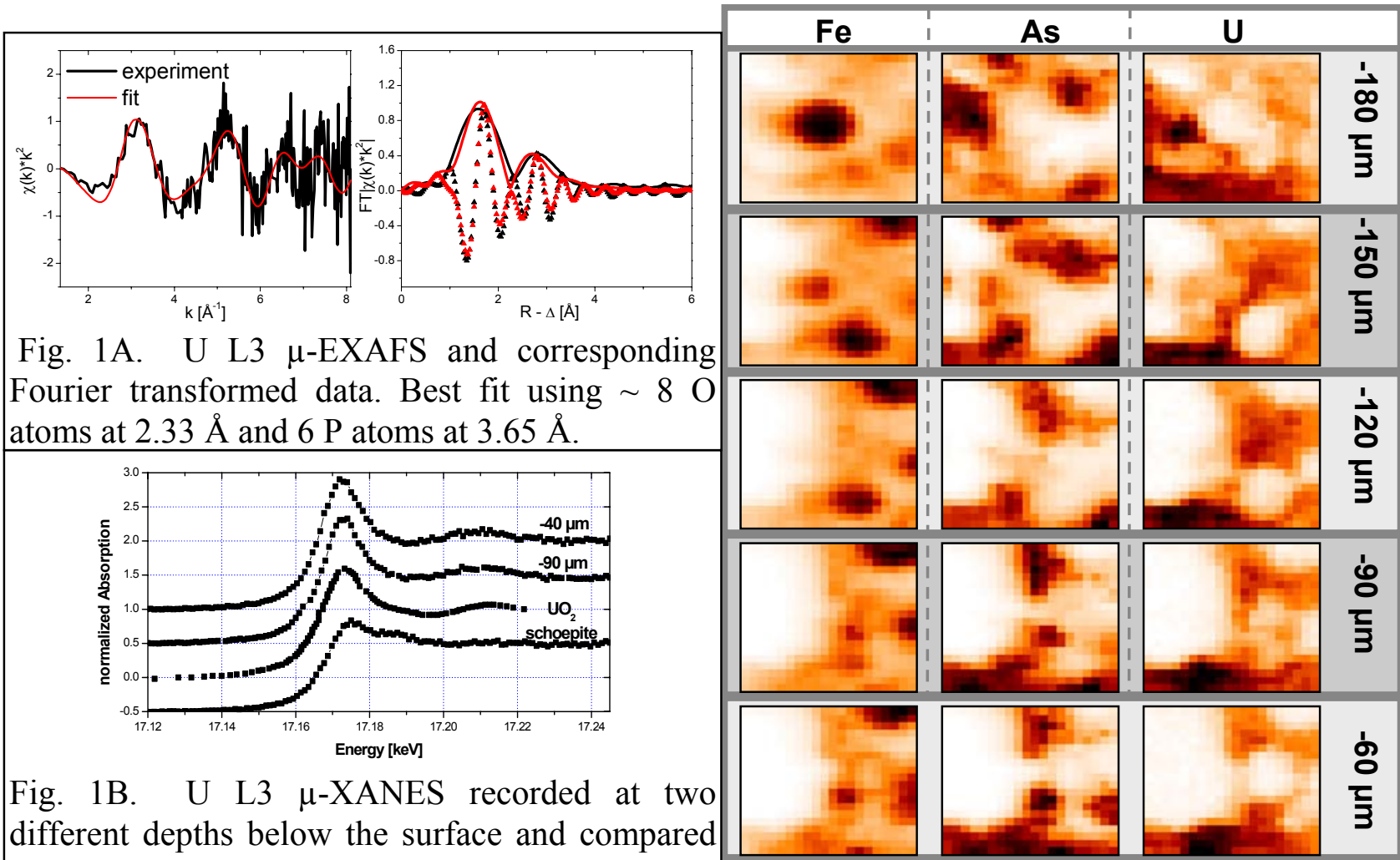

Fig. 1A. U L3 $\mu$-EXAFS and corresponding Fourier transformed data. Best fit using $\sim 8 \mathrm{O}$ atoms at $2.33 \AA$ and $6 \mathrm{P}$ atoms at $3.65 \AA$.

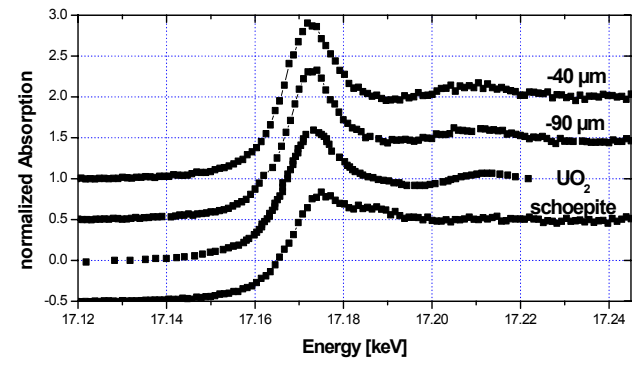

Fig. 1B. U L3 $\mu$-XANES recorded at two different depths below the surface and compared to U(IV) and U(VI) reference sample XANES.

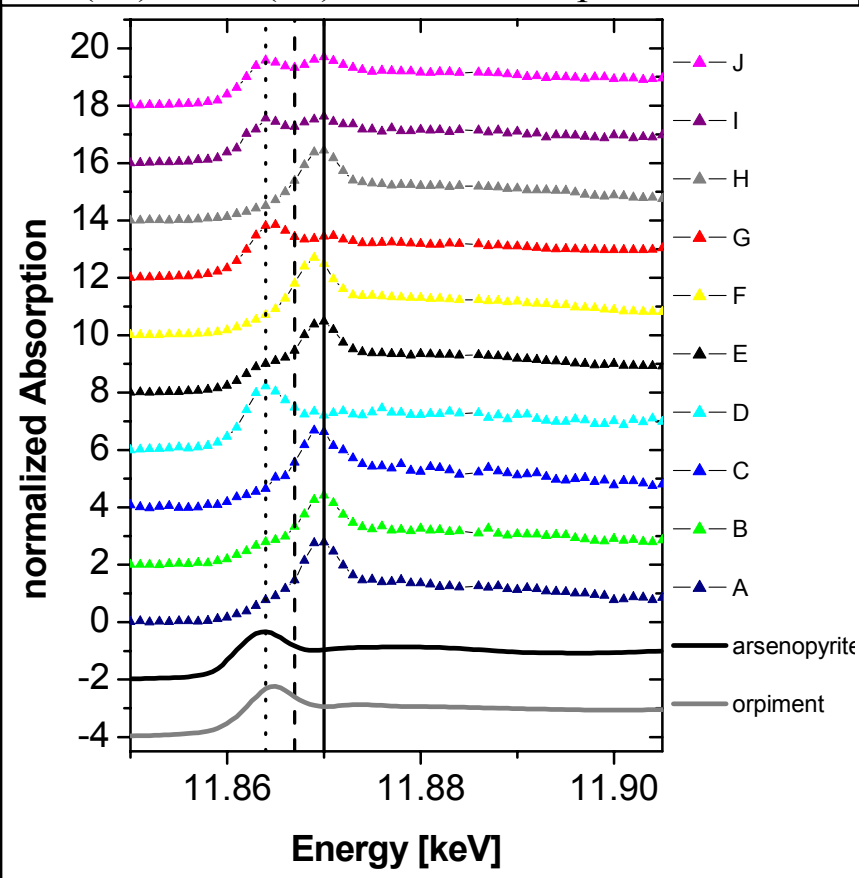

FIG. 3. As $\mathrm{K} \mu$-XANES recorded at various positions and depths below the sample surface (A$\mathrm{J})$ and compared to that of arsenopyrite and orpiment and energy positions expected for As(0) (dots), As(III) (dashed), and As(V) (continuous).

Fig 2. Fe, As, and $U$ distribution maps at indicated depths below the surface of a $300 \times 300 \mu \mathrm{m}^{2}$ sample section $\left(20 \times 20 \mu \mathrm{m}^{2}\right.$ step size $)$; optical photograph at left.

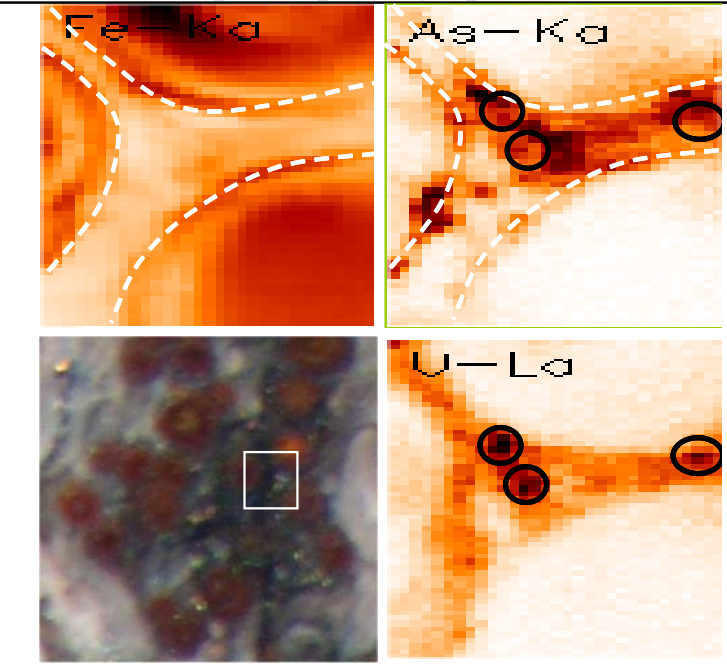

FIG. 4. Confocal $\mu$-XRF maps of a $120 \mathrm{x}$ $120 \mu \mathrm{m}^{2}$ section $\left(2 \times 4 \mu \mathrm{m}^{2}\right.$ step size) $-60 \mu \mathrm{m}$ below the surface. Circles indicate $U$ hotspots, dashed lines an As-rich rim on Fe(II)nodule; optical image lower left. 